\title{
Turbulent Burning of a Flat Fuel Surface
}

\author{
L. ZHOU and A. C. FERNANDEZ-PELLO \\ Department of Mechanical Engineering \\ University of California at Berkeley \\ Berkeley, California 94720 , USA
}

\begin{abstract}
Experiments have been conducted to study the effect of flow velocity and gridgenerated turbulence intensity on the surface regression rate of thick PMMA sheets burning in a forced air flow. All the tests are carried out in a laboratory-scale combustion tunnel with flow velocities ranging from $1 \mathrm{~m} / \mathrm{s}$ to $4 \mathrm{~m} / \mathrm{s}$ and turbulence intensities from $1 \%$ to $20 \%$. It is found that for all turbulence intensities, the regression rate decreases with the distance from the fuel sheet upstream edge, and increases with the flow velocity, in agreement with boundary layer analyses of the process. It is also found that flow turbulence has a strong influence on the surface regression rate due primarily to an enhancement of the heat transfer from the flame to the fuel that is caused by turbulence generated flame fluctuations. It is shown that the experimental data can be correlated in terms of a non-dimensional mass burning rate, $\dot{\mathrm{m}}^{\prime \prime} \mathrm{Lx} /\left(\lambda\left(\mathrm{T}_{\mathrm{f}}-\mathrm{T}_{\mathrm{p}}\right)\right)$ that is approximately linearly proportional to the turbulent flow parameter $\left(\left(\mathrm{u}^{\prime} / \mathrm{u}\right)_{\infty} \operatorname{Re}_{\mathrm{x}}^{0.8}\right)^{0.5}$. The good correlation of the data in terms of these parameters indicate the potential predictive capabilities of theoretical models of the process that incorporate the flow turbulence through an eddy viscosity, and thermal and mass diffusivities. Explicit expressions for the laminar and turbulent mass burning rates in terms of the solid fuel and flow properties are reported.
\end{abstract}

\section{NOMENCLATURE}

$\begin{array}{ll}\mathrm{a} & \text { Constant } \\ \mathrm{c}_{\mathrm{p}} & \text { Gas specific heat } \\ \mathrm{f} & \text { Normalized stream function } \\ \mathrm{L} & \text { Heat of pyrolysis } \\ \mathrm{M} & \text { Molecular weight } \\ \dot{\mathrm{m}}^{\prime \prime} & \text { Mass burning rate } \\ \mathrm{Q}^{\prime \prime} & \text { Heat of combustion } \\ \dot{\mathrm{q}}_{\mathrm{c}}^{\prime \prime} & \text { Convective surface heat flux } \\ \dot{\mathrm{q}}_{\mathrm{r}}^{\prime \prime} & \text { Radiative surface heat flux } \\ \mathrm{R}_{\mathrm{x}} & \text { Reynolds number, } \mathrm{u}_{\infty} \mathrm{x} / \mathrm{V} \\ \dot{\mathrm{r}} & \text { Surface regression rate } \\ \mathrm{T} & \text { Temperature } \\ \mathrm{u} & \text { Velocity parallel to the fuel surface } \\ \left(\mathrm{u}^{\prime} / \mathrm{u}\right)_{\infty} & \text { Turbulence intensity at the free stream } \\ \mathrm{v} & \text { Velocity normal to the fuel surface } \\ \mathrm{x} & \text { Coordinate parallel to the fuel surface } \\ \mathrm{Y}_{\mathrm{i}} & \text { Mass fraction } \\ \mathrm{y} & \text { Coordinate normal to the fuel surface } \\ \mathrm{Z} & \text { Mixture fraction, }\left(\beta-\beta_{\infty}\right) /\left(\beta_{\mathrm{p}}-\beta_{\infty}\right) \\ \mathrm{Greek} & \text { Symbols } \\ \alpha & \text { Thermal diffusivity } \\ \beta_{\mathrm{F}} & \text { Species Shvab-Zeldovich variable, } \mathrm{Y}_{\mathrm{F}} / v_{\mathrm{F}} \mathrm{M}_{\mathrm{F}}-\mathrm{Y}_{\mathrm{o}} / v_{\mathrm{o}} \mathrm{M}_{\mathrm{o}}\end{array}$




\begin{tabular}{ll}
$\beta_{\mathrm{T}}$ & Temperature-species Shvab-Zeldovich variable, $c_{\mathrm{p}} \mathrm{T} / \mathrm{Q}-\mathrm{Y}_{\mathrm{o}} / N_{\mathrm{o}} \mathrm{M}_{\mathrm{o}}$ \\
$\varepsilon$ & Eddy kinematic viscgsity and diffusivity, $\mathrm{a}\left(\mathrm{u}^{\prime} / \mathrm{u}\right)_{\infty} \mathrm{u}_{\infty} \mathrm{y}$ \\
$\eta$ & Similarity variable, $\sqrt{\mathrm{u}_{\infty} / v \mathrm{x}}$ \\
$\lambda$ & Thermal conductivity \\
$\nu$ & Kinematic viscosity, also stoichiometric coefficient \\
$\rho$ & Density \\
$\psi$ & Stream function, $\sqrt{\mathrm{v \textrm {u } _ { \infty }} \times \mathrm{f}}(\eta)$ \\
Subscripts & \\
\hline $\mathrm{F}$ & Fuel \\
$\mathrm{f}$ & Flame \\
$\mathrm{o}$ & Oxygen \\
$\mathrm{p}$ & Pyrolysis \\
$\mathrm{s}$ & Solid \\
$\infty$ & Free stream \\
- & Gas phase
\end{tabular}

\section{INTRODUCTION}

The surface regression, or mass burning rate of a solid combustible burning in a convective oxidizing gas flow is an important subject in problems related to the development of fires, material processing and rocket propulsion. Specifically in a fire, it determines such aspects of the problem as flame heights, rate of heat release, and smoke and CO emission, among others, which in turn determine the growth rate of the fire and its potential hazard. A configuration of this combustion process encountered in practical situations and amiable to theoretical modeling, is that of a flat solid fuel surface burning in an oxidizer gas flowing parallel to the solid surface. The resulting combustion problem is that of a diffusion flame established in the boundary layer adjacent to the fuel surface. The solid pyrolysis is caused and sustained by heat transfer from the diffusion flame to the solid surface. The characteristics of the diffusion flame and of the heat transferred from the flame to the surface, and consequently of the mass burning rate, depend strongly on the characteristics of the gaseous flow in addition to the solid properties. Since most practical combustion processes occur under turbulent flow conditions, it is of interest to investigate how the flow turbulence affects the heat transfer and chemical kinetic mechanisms that control the mass burning process.

A number of theoretical and experimental studies have been conducted of the laminar and turbulent burning of a flat fuel surface with a focus on fire applications. Emmons [1] in his analysis of the combustion of a flat liquid surface in a forced, laminar oxidizing flow established the foundations for the theoretical modeling of this problem. Using the boundary layer and flame sheet approximations he obtained explicit formulas for the mass burning rate in terms of the gas flow parameters and fuel properties. Kosdom et. al. [2] and Kim et. al. [3], applied the same methodology to develop analyses of the laminar, free convective burning of a vertical fuel surface, and conducted experiments that verified the mass burning rate predictions of the model. Mao et. al. [4] have developed a mixed convection formulation of the problem that gives the mass burning rate for the whole range of flow conditions from forced to free and for surfaces with different orientations. Sibulkin et. al. [5] have incorporated finite rate chemistry to the model and Mao et. al. [6] have developed a numerical analysis of the problem that removes both the boundary layer and flame sheet approximations. Further details on the problem can be found in the reviews of Pagni [7] and Sibulkin [8]. The theoretical formulation of the turbulent free convective burning of a vertical fuel surface has been developed by Kennedy and Plumb [9] and Tamanini [10] using infinite chemistry and Sibulkin [8] using finite rate kinetics. Experimental measurement and analysis can also be found from works done by Ahmad and Faeth [11], De Ris and Orloff [12] and Orloff et. al. $[13,14]$ among many others. These last studies focused on the mass 
burning rate of solid combustibles in a buoyantly-generated turbulent flow. The nondimensional burning rate was generally correlated with the Rayleigh Number, and in general, the experimental data agreed well with the theoretical predictions.

Another area related to the present work is the study of hybrid rocket fuel combustion. Notable among the different works published to date on the turbulent flow mass burning problem are those of Marxman and Gilbert [15], Marxman [16] and Paul et. al. [17] among others. The results of these works are generally presented in the form of relations between the regression rate and the mass transfer number $\mathrm{B}$. There are some similarities between these works and the present work, although these works are mainly concerned with hybrid rocket propellant burning in high speed flow and the present work is concerned primarily with the fire aspects of the process where low velocity flows prevail.

The turbulence in the studies mentioned above is either shear-generated or buoyantlygenerated, and the flow structure is usually very complex because turbulence generation and dissipation occur simultaneously. The other alternative to study flow turbulent effects is to introduce the turbulence artificially into the flow by means of a grid or perforated plate placed perpendicular to the flow direction. In grid-generated turbulent flow, the mean velocity gradient is very small so that the flow structure can be considered as isotropic and homogeneous, and, therefore, also relatively easier to model theoretically. Although considerable experimental and numerical works have been done on both premixed and diffusion free flames in shear-generated turbulent flows [18], the turbulent flow structure is so complex in shear-generated turbulent flow that the interaction between the flow and the flame is still far from clear. Therefore, it is useful to use simple turbulent flow such as grid flow to determine the relations between the flow and the flame. Even so, grid-generated turbulent diffusion flames have rarely been investigated, as indicated by Manako et. al. [19].

In the present work a systematic study has been carried out of the burning of a solid fuel in a forced, grid-generated turbulent air flow with the objective of experimentally determining the effect of the external flow velocity and turbulence intensity on the mass burning rate, and of finding proper correlations between the burning rate and the flow parameters.

\section{EXPERIMENT}

The experimental apparatus is shown schematically in Fig. 1. It consists of a laboratory scale wind tunnel designed to conduct combustion experiments under varied flow conditions, and the supporting instrumentation. The wind tunnel has a $0.89 \mathrm{~m}$ long settling chamber with a rectangular cross section $0.31 \mathrm{~m}$ by $0.18 \mathrm{~m}$, which supplies gas flow to the tunnel test section through a converging nozzle with a reduction area of 5.5 to 1 . The test section is $0.61 \mathrm{~m}$ long and has rectangular cross section $0.122 \mathrm{~m}$ wide and $76 \mathrm{~mm}$ high. The side walls of the test section are made of $6 \mathrm{~mm}$ thick Pyrex glass for visual observation and optical diagnostic access, and the floor and ceiling are made of $55 \mathrm{~mm}$ thick Marinite sheet. The combustion tunnel is positioned horizontally on a three axis positioning table.

The air flow in the test section is supplied from a centralized gas compressor and the flow rates controlled with critical flow nozzles. Turbulence is generated by means of grids, or perforated placed at the exit of the tunnel converging nozzle. A prescribed turbulence intensity is obtained through a combination of flow velocity and plate blockage ratio. The blockage ratio varies from 0 to 0.8 . A detailed description of the velocity and turbulence profiles through the test section is given in Ref. [20]. The air flow velocity and turbulence intensity are measured with a one-component Laser Doppler Velocimeter operating in the forward scattered mode. The experimental installation also includes a Schlieren system with a $0.45 \mathrm{~m}$ diameter collimated light beam and an array of eight thermocouples that is used to measure and monitor the solid combustible surface temperature. 


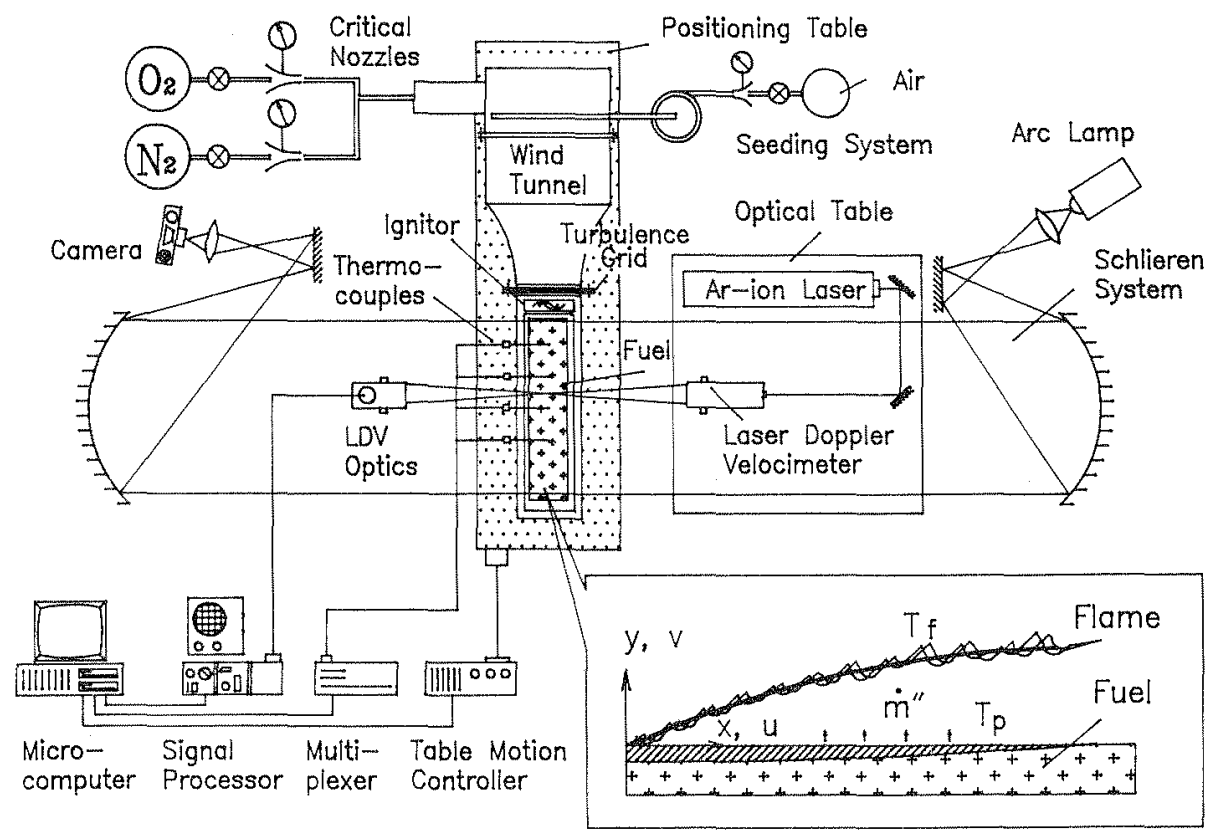

1. Schematic of the experimental installation.

'The fuel specimens used in this work are $12.7 \mathrm{~mm}$ thick PMMA (polymethyl methacrylate) (Roam and Hass, Plexiglas $G$ ) sheets, $76 \mathrm{~mm}$ wide by $0.37 \mathrm{~m}$ long. PMMA was selected because of its non-charring burning. The fuel samples are mounted flush in the tunnel Marinite floor with their upstream edge placed $0.1 \mathrm{~m}$ from the tunnel convergent nozzle exit. The PMMA burning is initiated by igniting the upstream edge of the sheet with an electrically heated nichrome wire. The flame is left to spread over the solid surface and the arrival of the pyrolysis front at a given thermocouple is recorded to mark the initiation of the mass burning process at that particular location. After the fuel sample has burnt for about 20 minutes, the flame is extinguished with nitrogen in less than 20 seconds. The burnt sample sheets is cut along the longitudinal center line, its surface smoothed, and its thickness measured at the positions along the center line where the thermocouples were located. The regression rate is calculated by dividing the slab thickness difference before and after burning by the effective burning time, which is obtained from the temperature history by subtracting the time of pyrolysis front arrival from the total burning time. All the experiments were conducted with air as oxidizer, and for flow velocities and turbulence intensities ranging from 1 to $4 \mathrm{~m} / \mathrm{sec}$ and 1 to $20 \%$ respectively.

\section{EXPERIMENTAL RESULTS}

A characteristic example of the measured surface regression rate along the PMMA sheet length is presented in Fig. 2 for an air flow velocity of $2 \mathrm{~m} / \mathrm{s}$ and for several turbulent intensities. The data are averaged from three tests and the standard deviation is $10 \%$. The regression rate measurements at other flow velocities have similar functional dependences as those shown in the figure. From the results of Fig. 2, it is seen that for all turbulence intensities the regression rate decreases with the distance from the upstream edge of the PMMA sample, the effect being more pronounced as the turbulence intensity is increased. This trend 
is in qualitative agreement with the theoretical predictions from flat plate boundary layer mass burning analyses $1,7,8$, at least for laminar flow. In this process, heat transfer from the flame to the solid determines the rate of solid pyrolysis, and consequently of mass burning, and since the boundary layer grows thicker downstream, the flame moves away from the surface and the heat transferred by convection to the solid is reduced downstream. As a consequence, the surface regression and the mass burning rates decrease as the distance from the PMMA sheet leading edge increases, in agreement with the results of Fig. 2. The results of Fig. 2 and all the other measurements, also show that the flow turbulence affects the regression rate substantially, and that the regression rate can more than double when the turbulence intensity is increased from $1 \%$ to $20 \%$.

The air flow velocity effect on the regression rate along the PMMA sheet is presented in Fig. 3 for a flow turbulence intensity of $10 \%$. It is seen from this figure that throughout the fuel length, the regression rate is an increasing function of the flow velocity. Similar results are also obtained at other flow turbulence intensities. The functional dependence of the regression rate on the flow velocity is also in agreement with the predictions from boundary layer mass burning analyses $[1,7,8]$. As the flow velocity is increased, the boundary layer becomes thinner and the flame moves closer to the fuel surface. The result is an enhancement of the convective heat transfer from the flame to the fuel and therefore is an increase of the regression rate, as obtained in the measurements of Fig. 3.

\section{DATA CORRELATION}

The qualitative agreement between the regression rate measurements and the predictions of the boundary layer analyses suggests the correlation of the experimental data in

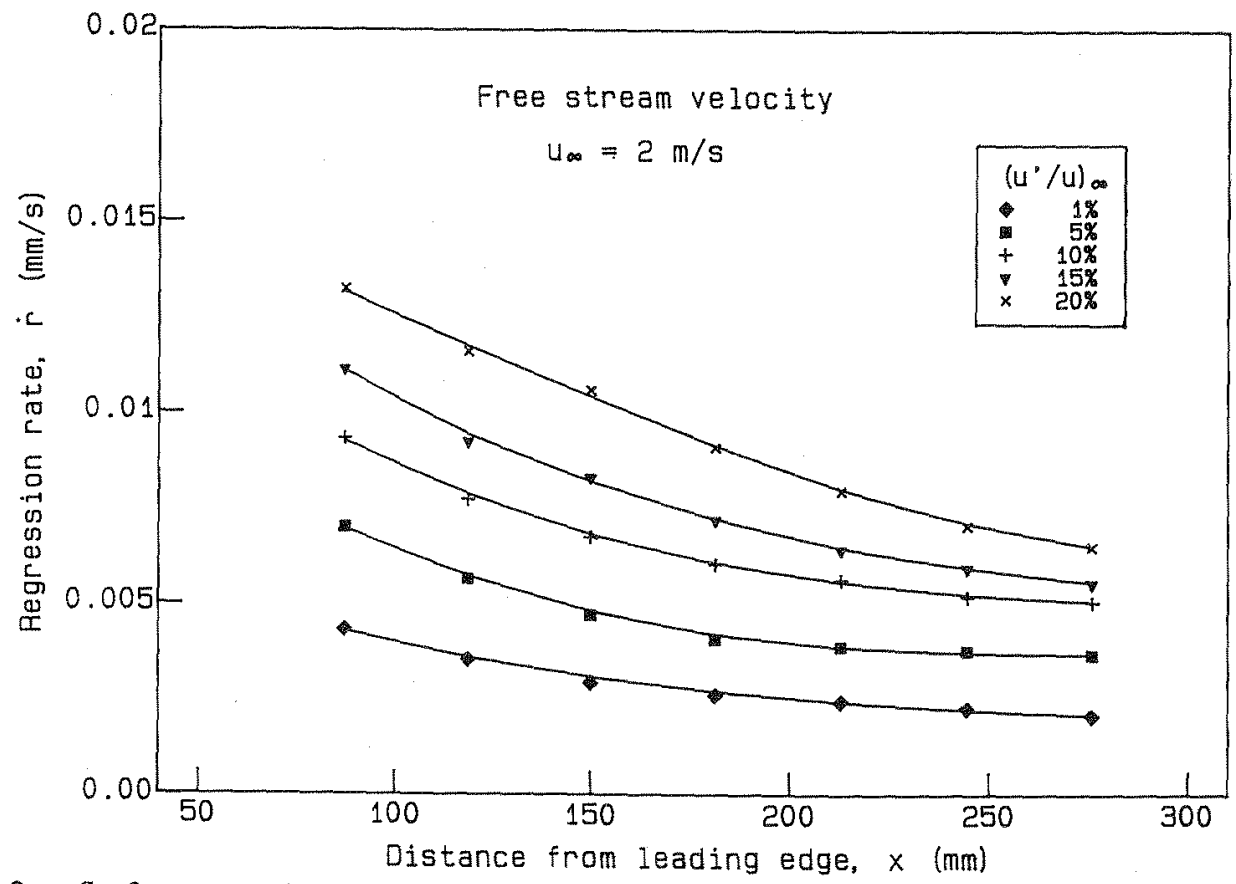

2. Surface regression rate along the PMMA sheet for air flow velocity of $2 \mathrm{~m} / \mathrm{s}$ and several turbulence intensities. 


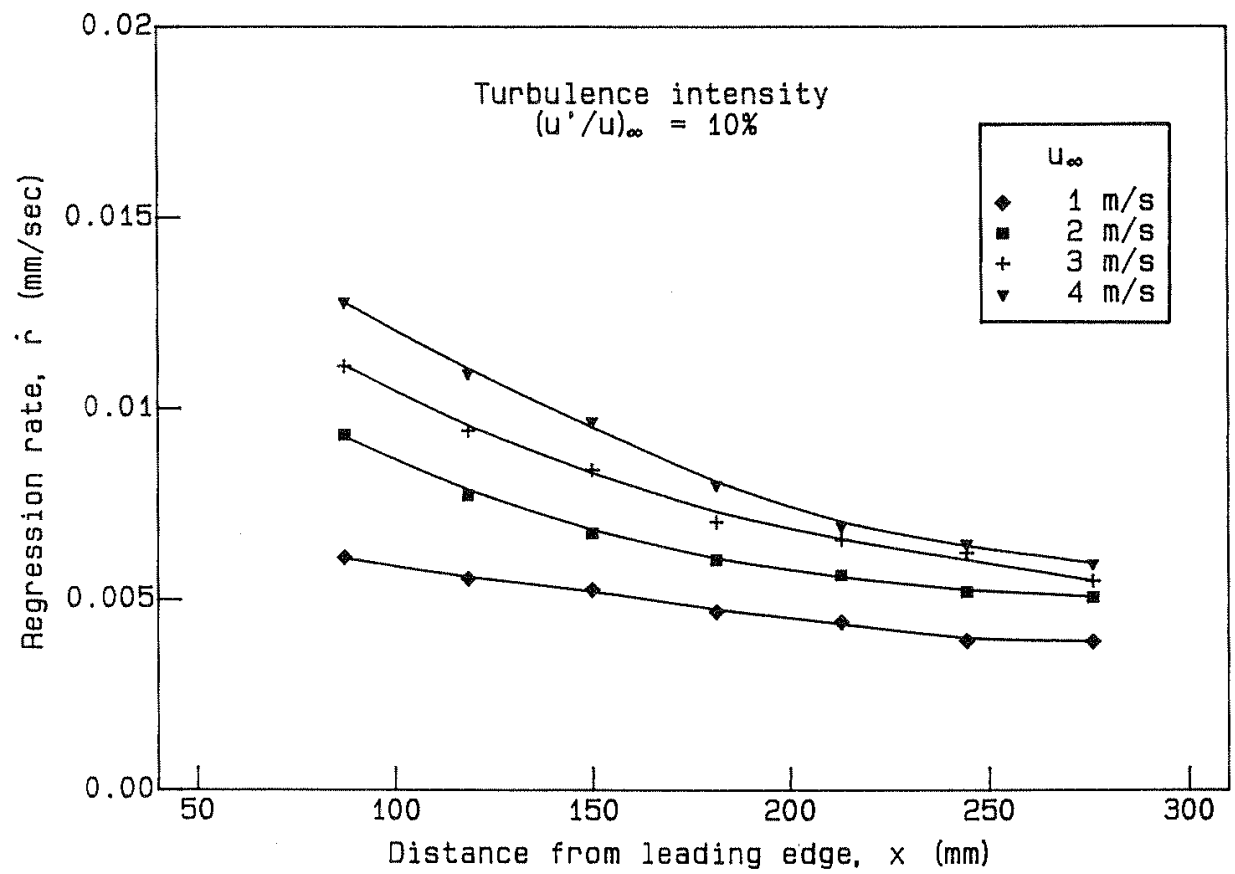

3. Surface regression rate along the PMMA sheet

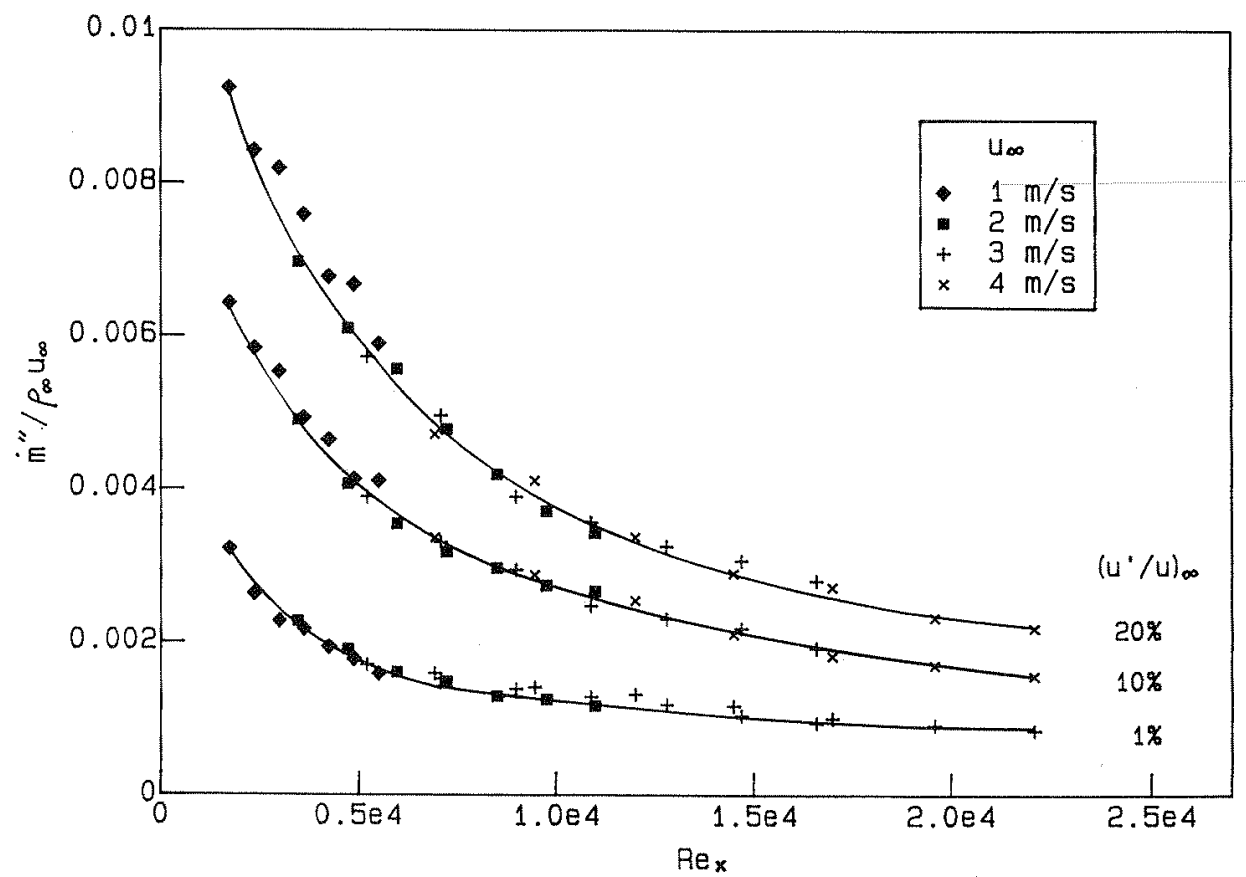

4. Non-dimensional regression rate versus Reynolds number 
terms of the non-dimensional variables that can be extracted from these analyses. In Fig. 4, the regression rate data is correlated in terms of a non-dimensional burning rate $\dot{\mathrm{m}}^{\prime \prime} / \rho \mathrm{u}_{\infty}$ and the Reynolds number, as proposed by Emmons [1]. The data correlated are for all the flow velocities tested and turbulence intensities of 1,10 and $20 \%$. The results of Fig. 4 show that for a given turbulence intensity, the regression rate data correlate well with the selected nondimensional parameters, which suggests that the turbulence intensity should be included as one of the non-dimensional parameters in the correlation. In this regard, the analysis of the Smith [21] for the convective heat transfer in a turbulent stagnation point flow, provides a potential method to incorporate the turbulence intensity in an analysis of the present mass burning problem and to deduce the proper non-dimensional parameter to correlate the experimental data. Following Smith's analysis, an eddy kinematic viscosity and diffusivity is defined in the form $\varepsilon=a\left(u^{\prime} / u\right)_{\infty} u_{\infty} y$, so that it includes the turbulence intensity and the shear stress, and heat and mass fluxes are then expressed in terms of the laminar, plus the turbulent eddy contribution. With the coordinate origin at the upstream fuel sheet edge, introducing the similarity variable $\eta=y \sqrt{u_{\infty}} / v x$, and assuming that there is a locally similar solution of the problem such that the stream function can be expressed as $\psi=V_{v} u_{\infty} \times f(\eta)$ and the mixture fraction as $\mathrm{Z}=\mathrm{Z}(\eta)$, the flat plate boundary layer conservation equations that describe the problem can then be written in the form

$$
\begin{aligned}
& {\left[1+a\left(\frac{u^{\prime}}{u}\right)_{\infty} \operatorname{Re}_{x}^{1 / 2} \eta\right] f^{\prime}+a\left(\frac{u^{\prime}}{u}\right)_{\infty} \operatorname{Re}_{x}^{1 / 2} f^{\prime \prime}+\frac{1}{2} f^{f^{\prime \prime}}=0} \\
& {\left[1+a\left(\frac{u^{\prime}}{u}\right)_{\infty} \operatorname{Re}_{x}^{1 / 2} \eta\right] Z^{\prime \prime}+\left[\frac{1}{2} f+a\left(\frac{u^{\prime}}{u}\right)_{\infty} \operatorname{Re}_{x}^{1 / 2}\right] Z^{\prime}=0}
\end{aligned}
$$

where $\mathrm{Z}$ is the mixture fraction [22] is formulated in terms of the Shvab-Zeldovich temperature and species coupling functions and where infinite chemistry is assumed [7,22]. The boundary conditions for the above equations are $f(0)=f^{\prime}(0)=0$, $\mathrm{f}^{\prime}(\infty)=1, \mathrm{Z}(0)=1$, and $\mathrm{Z}(\infty)=0$. The non-dimensional mass burning rate is then given by

$$
\frac{\dot{\mathrm{m}}^{\prime \prime} \mathrm{Lx}}{\lambda\left(\mathrm{T}_{\mathrm{f}}-\mathrm{T}_{\mathrm{p}}\right)}=\left.\operatorname{Re}_{\mathrm{x}}^{1 / 2} \frac{\partial \mathrm{Z}}{\partial \eta}\right|_{\eta=0}
$$

From Eqs. (1) to (3), it is seen that the solution of the problem has as parameter the product $\left(u^{\prime} / u\right)_{\infty} \operatorname{Re}_{x}^{1 / 2}$, and therefore that the value of $(\partial Z / \partial \eta)_{\eta=0}$, and consequently of the mass burning rate, will be a function of this flow parameter. Thus, it can be inferred that $\left(u^{\prime} / \mathrm{u}\right)_{\infty} \operatorname{Re}_{\mathrm{x}}^{1 / 2}$ should be the proper parameter to correlate the experimental data since it describes the flow characteristics through the turbulence intensity and Reynolds number, and appears as parameter in the solution of the governing equations of the problem.

Correlation of the laminar flow surface regression rate data in terms of the nondimensional mass burning rate (Eq. (3)) and the square root of the Reynolds number is presented in Fig. 5. The data used in the correlation is the following: $\mathrm{L}=1.58 \times 10^{3} \mathrm{KJ} / \mathrm{kg}$, $\mathrm{T}_{\mathrm{f}}=1380 \mathrm{~K}, \mathrm{~T}_{\mathrm{p}}=663 \mathrm{~K}, \lambda=6.7 \times 10^{-2} \mathrm{~W} / \mathrm{mK}, \mathrm{v}=1.26 \times 10^{-4} \mathrm{~m}^{2} / \mathrm{s}$. It is seen that there is a linear dependence between the two non-dimensional parameters as predicted in laminar, flat plate, boundary layer models of the problem [1,7,8]. From Fig. 5, the following expression is deduced for the mass burning rate

$\frac{\dot{\mathrm{m}}^{\prime \prime} \mathrm{Lx}}{\lambda\left(\mathrm{T}_{\mathrm{f}}-\mathrm{T}_{\mathrm{p}}\right)}=0.28 \mathrm{Re}_{\mathrm{x}}^{1 / 2}$ 


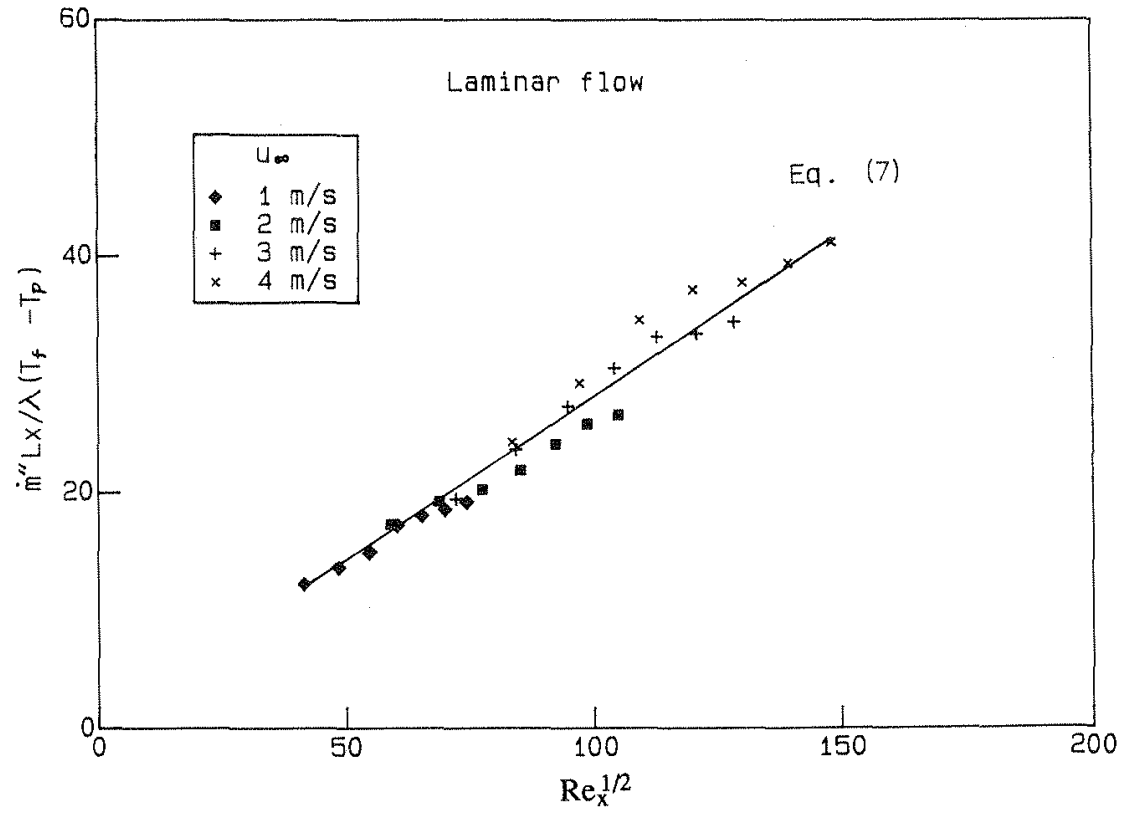

5. Non-dimensional mass burning rate for laminar flow versus the square root of the Reynolds number.

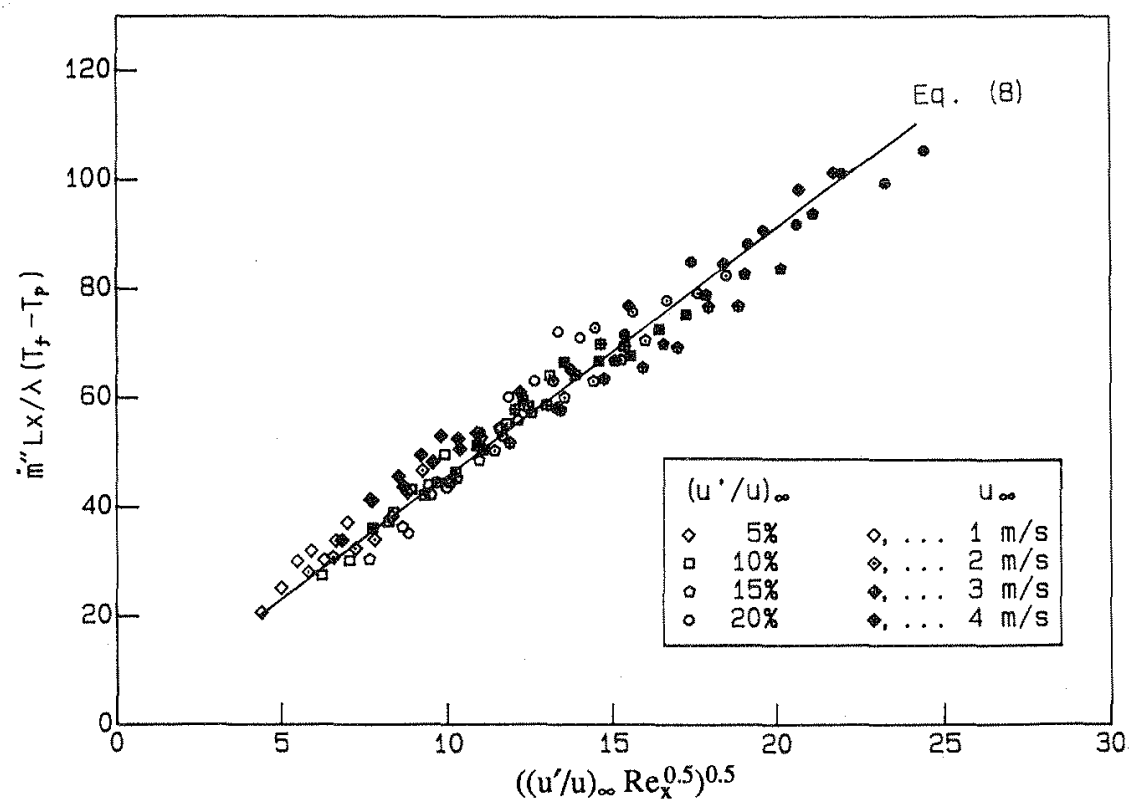

6. Non-dimensional mass burning rate for turbulent flow versus the non-dimensional flow parameter. 
which is the same expression that is obtained in non-reactive laminar flows for the surface Nusselt number [23].

Correlation of the turbulent flow surface regression rate data according to the predictions of Eq. (3), gives an approximately linear dependence between the non-dimensional mass burning rate and the square root of the turbulent flow parameter, i.e. $\left(\left(u^{\prime} / u\right)_{\infty} \operatorname{Re}_{x}^{0.5}\right)^{0.5}$, although the data is somewhat scattered. The scatter of the data is reduced if a 0.8 power is used in the Reynolds number, rather than the 0.5 power predicted in the analysis. This is reasonable since in non-reacting turbulent flows, it is also found that the Nusselt number correlates with the 0.8 power of the Reynolds number [23]. The results of the correlation of the turbulent flow surface regression rate measurements in terms of the non-dimensional mass burning rate (Eq. (3)) and the new turbulent flow parameter $\left(\left(u^{\prime} / u_{\infty} \operatorname{Re}_{\mathrm{x}}^{0.8}\right)^{0.5}\right.$ is presented in Fig. 6 for all tests conducted. It is seen that all the experimental data correlates very well with these non-dimensional parameters and that there is a linear relationship between them. From Fig. 6, the following explicit expression is deduced for the mas burning rate

$\frac{\dot{\mathrm{m}}^{\prime \prime} \mathrm{Lx}}{\lambda\left(\mathrm{T}_{\mathrm{f}}-\mathrm{T}_{\mathrm{p}}\right)}=4.5\left[\left(\frac{\mathrm{u}^{\prime}}{\mathrm{u}}\right)_{\infty} \mathrm{Re}_{\mathrm{x}}^{0.8}\right]^{0.5}$,

which provides the relationship between the mass burning rate and the fuel and oxidizing flow properties, and corroborates the potential predictive capabilities of the theoretical model introduced above.

The correlation of the data in terms of convective heat transfer parameters only indicates that for these particular experiments, radiation heat transfer from the flame to the solid has a secondary role. It should be noted, however, that the scale of these experiments is small and that as the size of the fuel sheet is increased, flame radiation will become increasingly important [12-14]. The model introduced above could be extended to approximately include flame radiation effects by applying the approach followed by Delitchatsios [24] in his analysis of the burning of large vertical walls in turbulent, natural convection flows.

\section{CONCLUSION}

Conducting mass burning rate experiments with non-charring, homogeneously burning solid fuel in a forced flow with grid induced turbulence, has permitted us to determine the effect of the flow parameters on the mass burning rate, and to obtain information useful in the development of theoretical models of solid fuel burning in turbulent flows. The results of the experiments show that flow turbulence can have a strong effect on the mass burning rate and that this effect is due primarily to the enhancement of the convective heat transfer at the fuel surface caused by the flame fluctuations. Correlation of the data shows that this effect can be expressed in terms of a turbulent flow parameter that includes both the Reynolds number and the turbulence intensity. It is interesting to note that the turbulence scale does not appear as a parameter in this correlation, even though one would expect that it would since the turbulence generating grids have different blockage ratios. A possible reason for this result is that the turbulence intensity decays slightly along the test section [20] while the turbulence scale grows and since both parameters have opposing effects, they may cancel each other. It also shows that boundary layer models that consider infinite chemistry and incorporate the flow turbulence through an eddy viscosity and diffusivity may be used to predict mass burning rates, at least in turbulent flows with a turbulent structure similar to that generated with grids. Finally, it should be indicated that buoyancy will play a role at low flow velocities. Recent results of the present authors show this effect very clearly when floor or ceiling burning surfaces are compared [25]. 


\section{ACKNOWLEDGEMENTS}

This work was supported by the National Institute of Standards and Technology under Grant No. 60NANB7D0737. Partial funds for the experimental facility were provided by a National Science Foundation Research Grant No. CBT-8506292.

\section{REFERENCES}

1. Emmons, H.W., Z. angew. Math. Mech., 36, p. 60, 1956.

2. Kosdom, F.J., Williams, F.A. and Buman, C., 12th Symp. (Int.) on Comb., p. 242, 1969.

3. Kim, J.S, de Ris, J. and Kroesser, F.W., I3th Symp. (Int.) on Comb., p. 949, 1971.

4. Mao, C.-P., Fernandez-Pello, A.C., and Pagni, P.J., J. Heat Transfer, 106, p. 304, 1984.

5. Sibulkin, M., Kulkarni, A.K., and Annamalai, K., Comb. and Flame, 44, p. 187, 1982.

6. Mao, C.-P., Kodama, H., and Fernandez-Pello, A.C. Comb. and Flame, 57, p. 209, 1984.

7. Pagni, P.J., Fire Safety J., 3, p. 273, 1980/81.

8. Sibulkin, M., Prog. Energy Combust. Sci., 14, p. 195, 1988.

9. Kennedy, L.A. and Plumb, O.A., 16th Sym. (Int.) on Comb., p. 1699, 1975.

10. Tamanini, F., 17th Symp. (Int.) on Comb., p. 1075, 1979.

11. Ahmad, T. and Faeth, G.M., 17th Symp. (Int.) on Comb., p. 1149, 1979.

12. De Ris, J. and Orloff, L., 16th Symp. (Int.) on Comb., p. 175, 1977.

13. Orloff, L., De Ris, J., and Markstein, G.H., 15th Symp. (Int.) on Comb., p. 183, 1975.

14. Orloff, L., Modak, A.T., and Alpert, R.L., 16th Symp. (Int.) on Comb., p. 1345, 1977.

15. Marxman, G.A. and Gilbert, M., 9th Symp. (Int.) on Comb., p. 371, 1963.

16. Marxman, G.A., I0th Symp. (Int.) on Comb., p. 1337, 1965.

17. Paul, P.J., Mukunda, H.S., and Jain, V.K., 19th Symp. (Int.) on Comb., p. 717, 1982.

18. Bilger, R.W., Prog. Energy Combust. Sci., 1, p. 87, 1976.

19. Manako, H., Ueda, T., and Mizomoto, M., Comb. Sci. and Tech., 59, p. 423, 1988.

20. Zhou, L. and Fernandez-Pello, A.C., Comb. and Flame, 81, p. 40, 1990.

21. Smith, M.C., The Physics of Fluids, 9, p. 2337, 1966.

22. Williams, F.A., Combustion Theory, 2nd Edition, Benjamin/Cummins, 1985.

23. Holman, J.D., Heat Transfer, 6th Edition, McGraw-Hill, 1986.

24. Delichatsios, M.A., 21st Symp. (Int.) on Comb., p. 53, 1986.

25. Zhou, L. and Fernandez-Pello, A.C., 1991 Spring Tech. Meet., WSS/CI, Boulder, CO, March, 1991. 